\title{
بناء مقياس التنمر الأخوي للى عينة من المراهقين
}

\author{
عايش صباح
}

Doi: //10.47015/17.3.6

تاريخ قبوله: 2020/7/20

تاريخ تسله البحث: 2020/4/25

\section{Developing a Measure of Fraternal Bullying among a Sample of Adolescents}

Aiche Sabah, Hassiba Ben Bouali University, Algeria

Abstract: The current study aims at developing the fraternal bullying scale in a sample of adolescents, verifying its structure through the factor analysis, as well as studying the differences in the level of fraternal bullying among adolescents according to the gender and age variables, The study was conducted on a sample of 221 pupils at Chlef and Ouargla states, who were chosen accidently. To achieve the objectives of the study, the descriptive approach was used based on the fraternal bullying scale built by the researcher, which consists of 26 items and measures two images of bullying: bullying on the brothers (victim) and bullying by the (bullying) brothers and measures three sub-dimensions of each image: physical, emotional and verbal bullying. The scale was presented to a group of psychologists, after which the statistical analysis of the scale was performed on the sample study. The results showed that there was a statistically significant correlation between the items and the scale as a whole through internal consistency and indications of acceptable stability, as indicated by conformity indicators. After conducting the confirmatory factor analysis, the model enjoyed a good overall match . There were also differences in the level of bullying on the brothers (victim) in favor of females, with the absence of differences between males and females in fraternal bullying of the image of the bullying brother. The study showed the existence of differences in the level of bullying according to the age variable and after using Scheffe post hoc test, it was reached that there are differences between two groups: first adolescence and middle adolescence.

(Keywords: Sibling Bullying, Scale)

وحتى النتائج المستقبلية خطرها كبير؛ إذ توصلت دراسة آدامز ولورانس إنس إنس إنس (Adams and Lawrence, 2011)

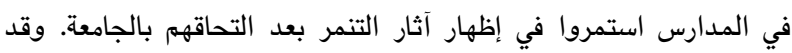

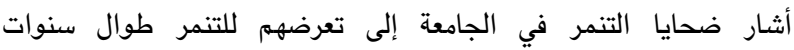

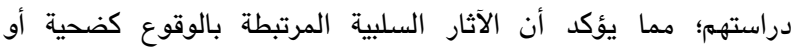

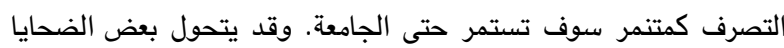

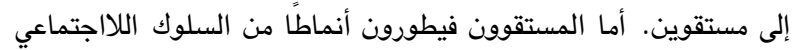

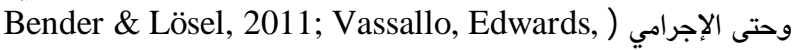

.) (Renda \& Olsson, 2014

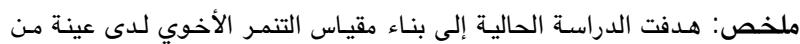

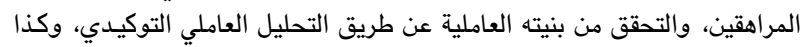

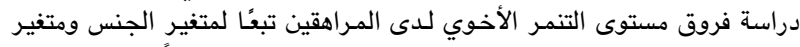

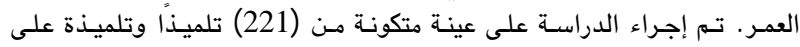

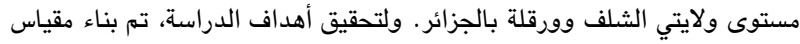

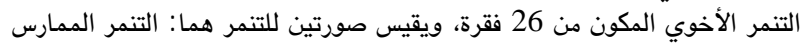

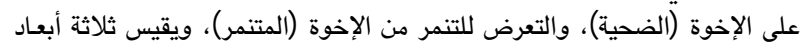

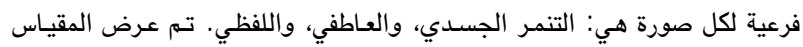

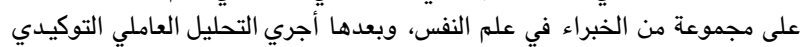

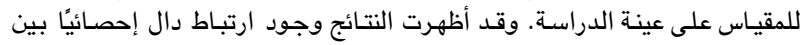

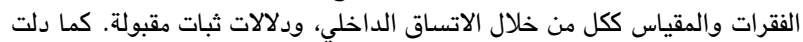

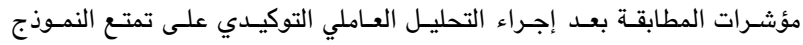

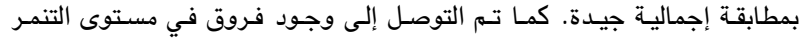

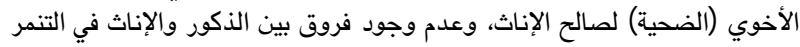

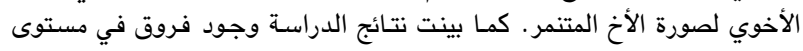

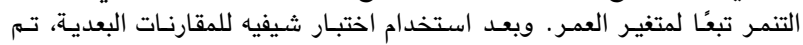

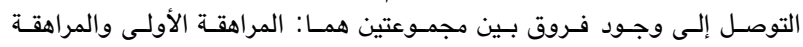

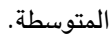
(الكلمات المفتاحية: مقياس، التنمر الأخوي)

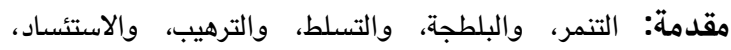

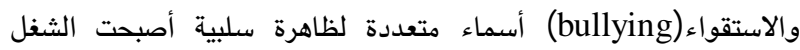

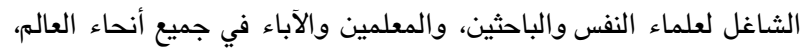

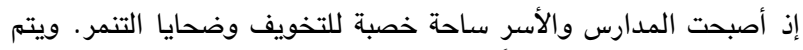

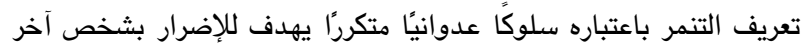

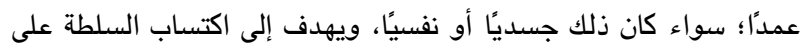

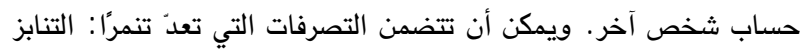

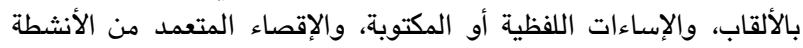

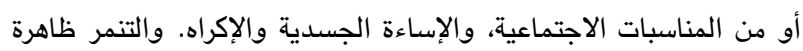

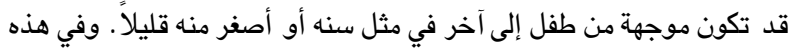

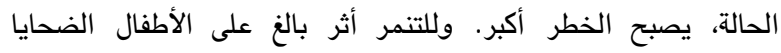

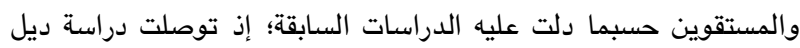
وآخرين (Dill et al.,2004) أن التنمر يتنبأ بالانسحاب الاجتماعي، فيما

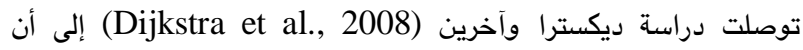

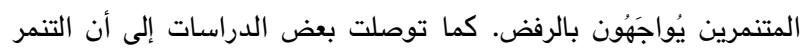

يؤدي إلى ضعف في الأداء الأكاديمي (Al-Raqqad et al., 2017) .

وتؤدي التصورات السلبية حول المدرسة أيضًا إلى التورط في التنمر

حسبما توصلت إليه دراسة هاريل فيش وآخرين ( 2011) التي تم تطبيقها على أربعين دولة من أوروبا وأمريكا الثمالية.

$$
\text { * جامعة حسيبة بن بوعلي، الشلف، الجزائر . }
$$
( حقوق الطبع محفوظة لجامعة اليرموك، إربد، الأردن، 2021. 
فالبحوث العملية لم تتطرق إلى مسألة ما إذا كان يمكن تصنيف العدوان أو إساءة المعاملة بين الإخوة على أنها تنمر.

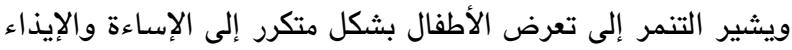
الموجه إليهم من قبل طفل أو مجموعة أطفال من ذوي القئ منكرل القوة الأكبر. وفي هذا الصدد، يشير ولكي وسكو ( Wolke and Skew, 2012) إلى أن الباحثين عندما يبلفون عن الإساءة والعيكو والعنف بين

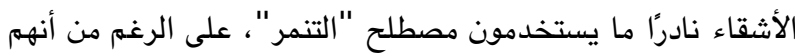

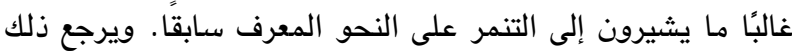

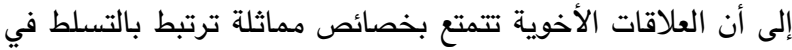

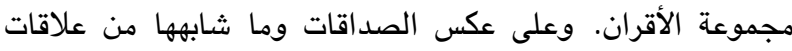

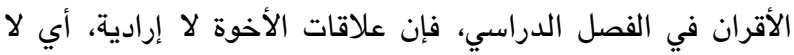

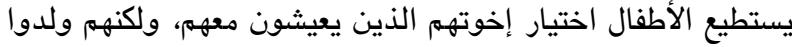

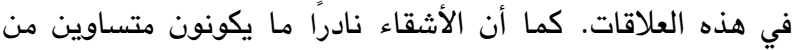

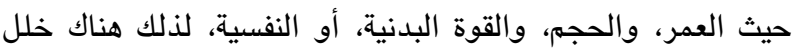

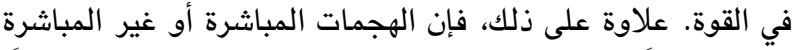

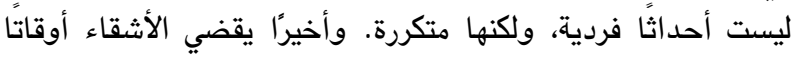

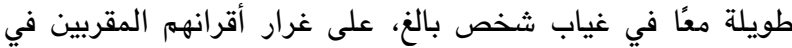

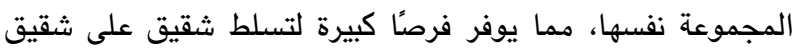

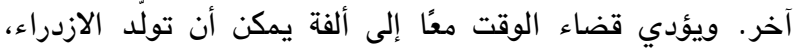
وهذا يعني أنهم يعرفون بالضبط كيف يثيرون أو يزعجون إخون إخوتهمه.

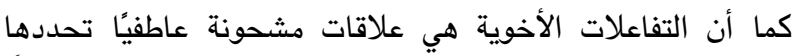
العواطف القوية غير المقيدة للجودة الإيجابية والسلبية وأحيانًا

المتناقضة .

ويرى نيلور وآخرون (Naylor et al., 2011) أن جميع أشكال العنف المنزلي تقريبًا، بما في ذلك العنف بين الأشقاء،

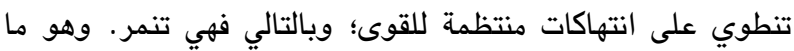
ذهب إليه (Wolke et al., 2015) الذين يرون أن غياب تعريف ولني

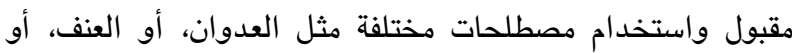

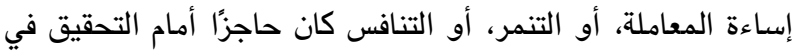

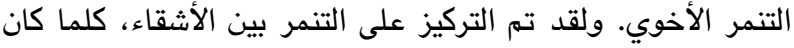

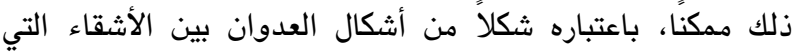

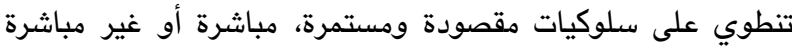

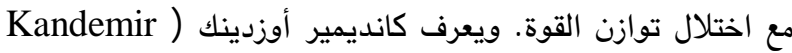
(Özdinç, 2019

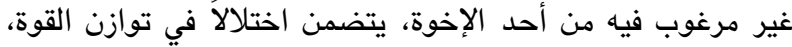

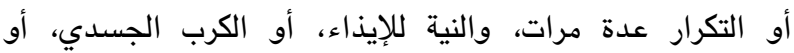

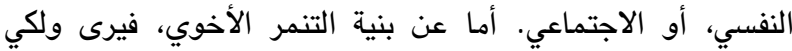
وآخرون (Wolke et al., 2015) أنها تشمل وضعين للتسلط الطي

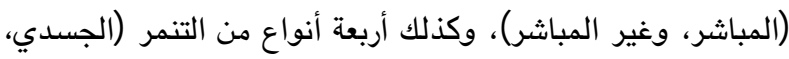
واللفظي، والعلائقي، وإلحاق الضرر بالممتلكات). ومن خلال هذا ولفيا

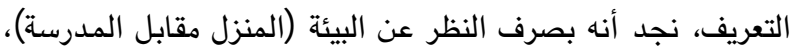

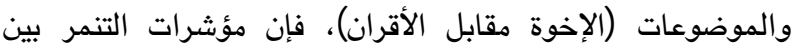

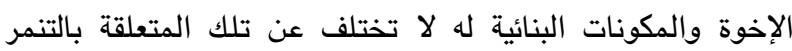

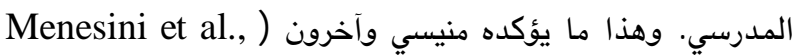

ويلعب الأشقاء دورا فريدا في حياة بعضهم أكثر من الآباء

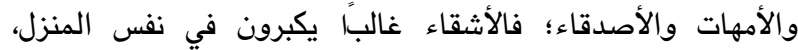

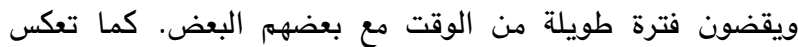

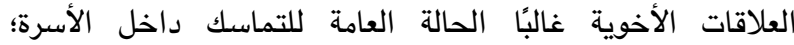
فالعلاقات الأخوية تلعب دوراً هامًا، ليس فقط في الحياة الأسرية،

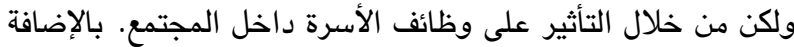
إلى ذلك، تؤثر العلاقات الأخوية في النمو الاجتماعي والمعرفي والعاطفي للأطفال (Vespo et al., 1995)؛ إذ يروى لئ تيبت وولك أن العلاقات الأخوية التي تتميز (Tippett and Wolke, 2015)

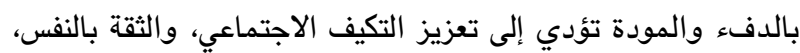
وتحسين الصداقة، والتقليل من احتمال جنوح المراهقيز تونين إلى تعاطي

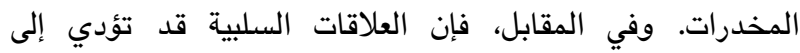

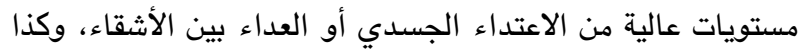

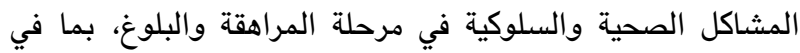

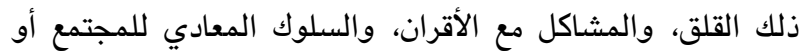

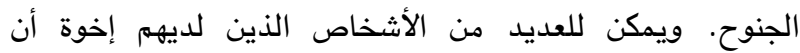
يتطرقوا إلى قصص التنافس بين الأشقاء وتبادل الاتهامات فيما

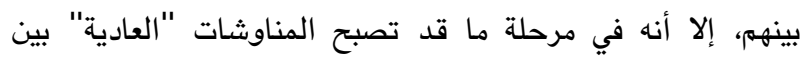

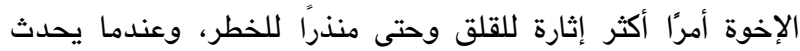
هذا، لا بد من المزيد من الاهتمام بهذه المشكلة.

لقد كان هذا السلوك بين الأقران موضوع بحث أثار الاهتمام

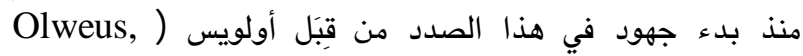

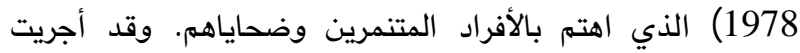

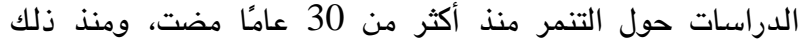

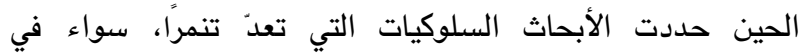
المدارس أو في أماكن أخرى (Hoetger et al., 2015)، ويعرفه أولويس (Olweus, 1993) بأنه تعرض الطالب للإيذاء والأعمال السلبية من جانب واحد أو أكثر من الطلبة الآخرين مرارًا وتكرارًا وبمرور الوقت، وتعرف بدارنة (Badarneh, 2012) التنمر بأنه

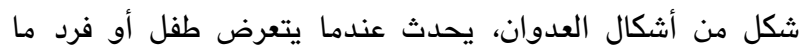

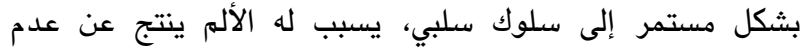
التكافؤ في القوى بين فردين؛ يسمى الأول متنمرًا والآخر ضحية.

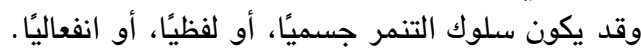

ومن الأشكال الأكثر شيوعًا للعدوان داخل الأسرة سلوكيات

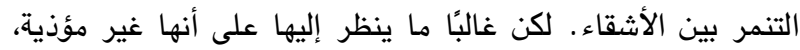

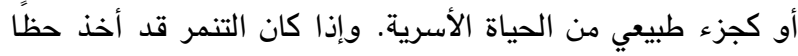

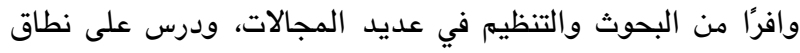

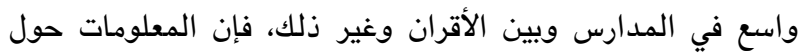
مدى وطبيعة هذه المشكلة بين الأشقاء في السياق الأسري لا تزال Abdul Majeed \& ) ناقصة، وتحتاج إلى دراسات لتوثيقها Hassan, 2017 ; Menesini \& Camodeca, 2008; . (Olweus, 1996; Olweus \& Limber, 2010 
التعاطف. كما وجدت دراسة دنكان (Duncan, 1999) أنه على

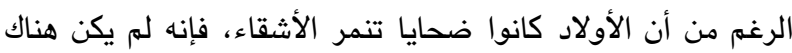

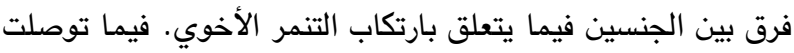

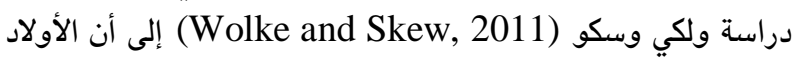

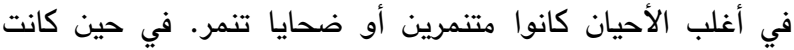

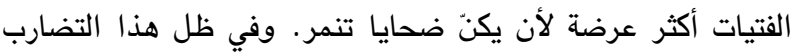

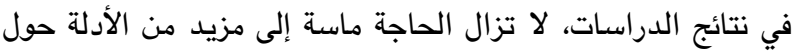

$$
\text { دور الجنس في التنمر الأخوي. }
$$

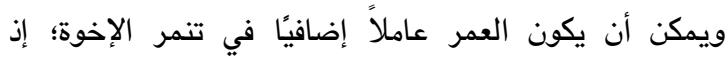

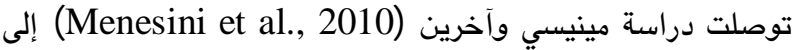

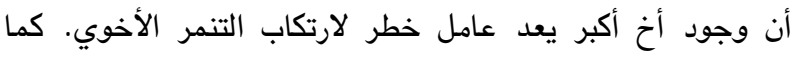

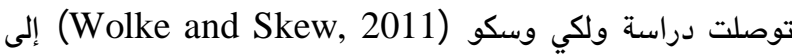

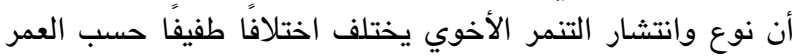

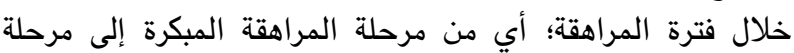

لاحقة.

وتكثف هذه الدراسات وغيرها مدى انتشار التنمر في

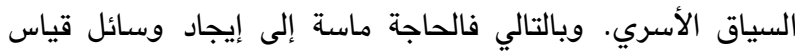

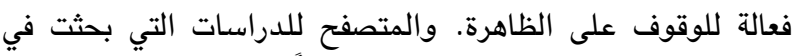

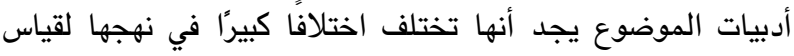

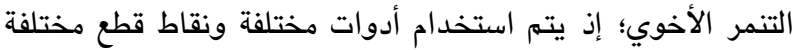

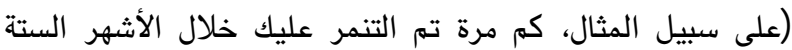

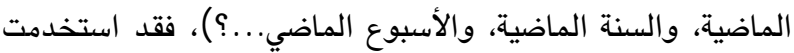
دراسة دنكان (Duncan, 1999) استبانة العلاقات مع الأقران، فيما استخدمت دراسة فينكلهور وآخرين ودراسة رادفورد وآخرين (Finkelhor et al., 2006; Radford et al., 2013) Juvenile Victimization ) ضحايا الأحداث Tippett and (Questionnaire بolke, 2015 فقد استخدمت مقياس التنمر الأخوي. وأما

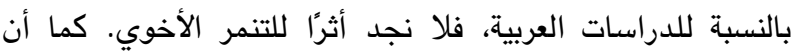

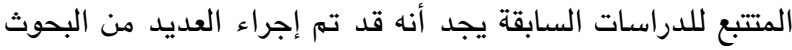

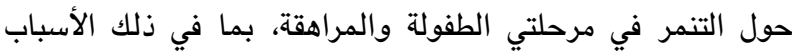

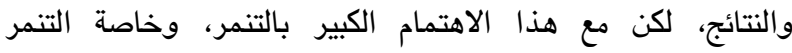

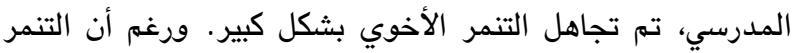

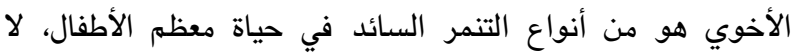

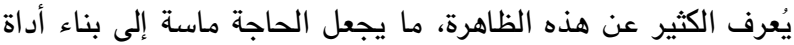

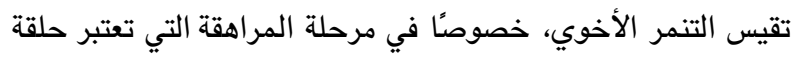

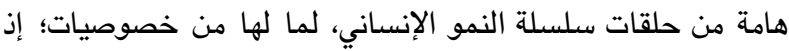

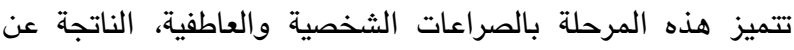

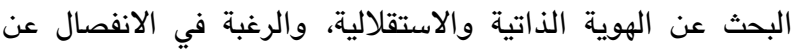

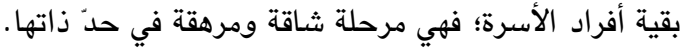
لذلك تسعى الدراسة الحالية إلى بناء مقياس للتنمر الأخوي

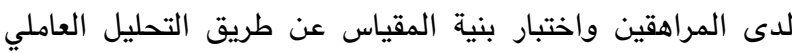
التوكيدي، وذلك من خلال محاولة الإجابة عن السؤالين التاليين:
2010) الذين يرون أنه على الرغم من أن الظاهرة تقدم خصائص

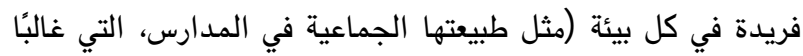

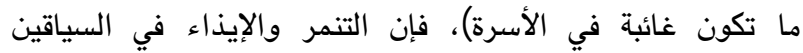

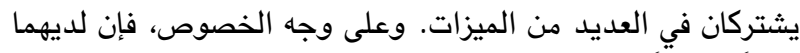

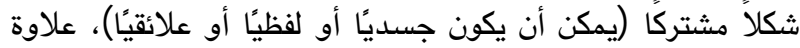

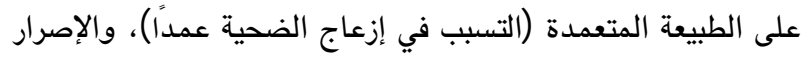
(تكرار الهجمات بمرور الوقت)، واختلال توازن القوة (المتنمر غالبًا ما يكون أقوى من الضحية الذي لا يستطيع الرد ). وتشير العديد من الدراسات إلى ارتفاع مستويات التنمر

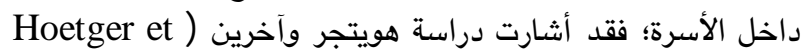
إلى أن الأشقاء ينظرون إلى سلوكيات التنمر بين التهائ (al., 2015

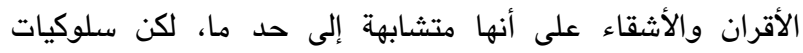

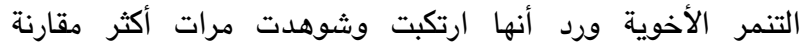

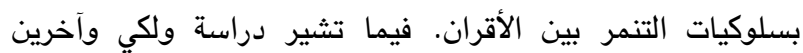
(Wolke et al., 2015)

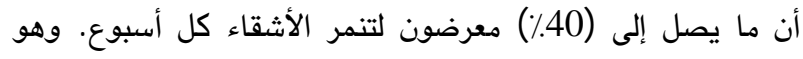

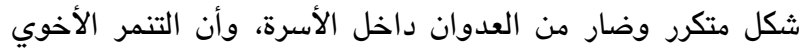

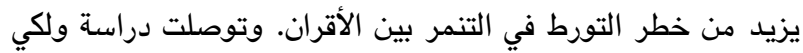

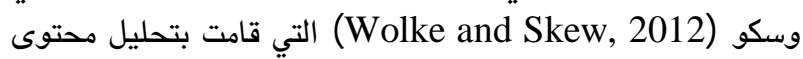

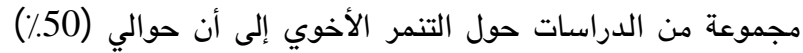

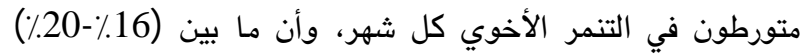

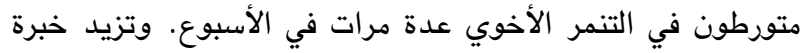

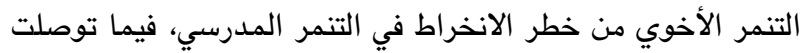

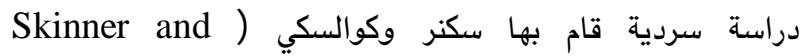
(Kowalski, 2013 إلى أنه من بين الأشقاء الذين شملهم الاستطلاع أفاد (78\%) أنها (18) ألى تعرضوا للتنمر من قبل الثقاء أشقائهم، و(85٪) أفادوا بإساءة إخوتهم لهم خلال طفولتهم.

وتساهم العوامل الأسرية في التنمر الأخوي، حيث يرى ولكي

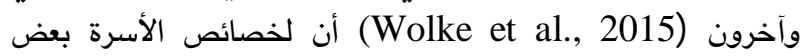

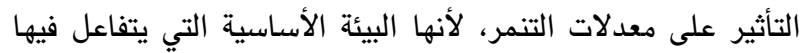

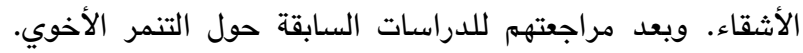

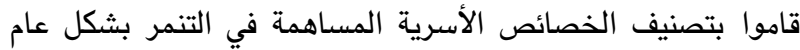
إلى ثلاث فئات: العوامل الهيكلية، وتثمل تكوين الأسرة، وعدد الأدية

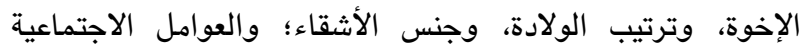

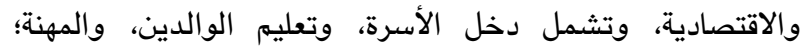
وسلوك الكبار أو القائم بالرعاية، مثل: سوء الأيرة، معاملة الأطفال؛

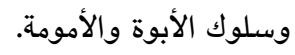

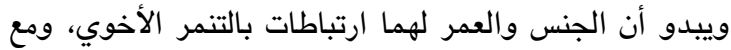

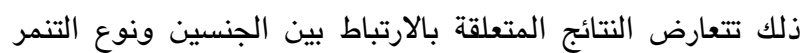

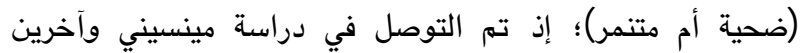
(Menesini et al., 2010)

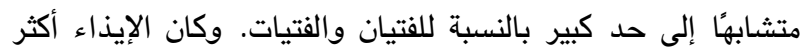
شيوعًا في سياق المستويات العالية من الصراع وانئ ولنفاض وكان الإيتاء مستويات 


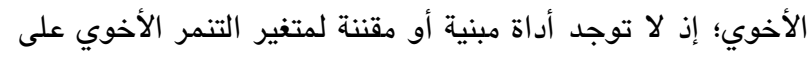

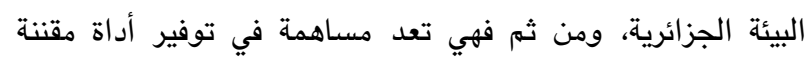
وموثوقة للباحثين.

$$
\text { حدود الدراسة }
$$

اقتصرت الدراسة الحالية على بناء مقياس التنمر الأخوي،

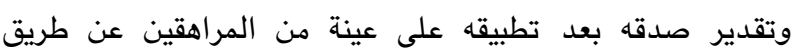

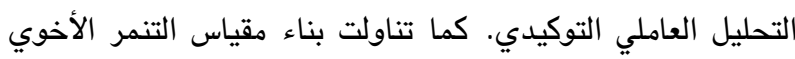

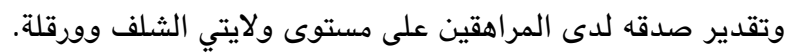

$$
\text { التعريفات الإجرائية }
$$

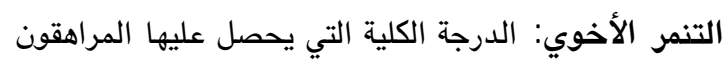

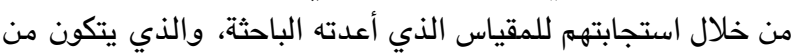

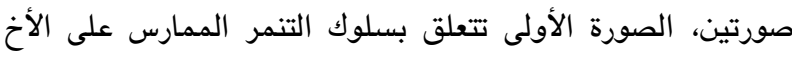

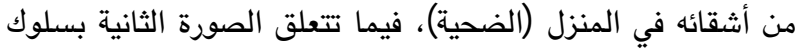
التنمر الممارس من الأخ على بقية إخوته (المتنمر).

\section{الطريقة}

مجتمع الدراسة وعينتها

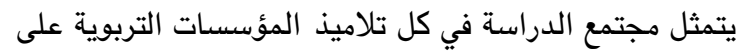

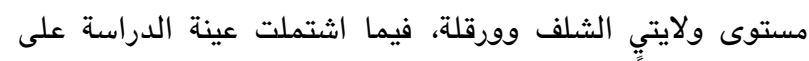

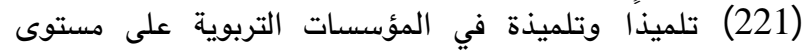

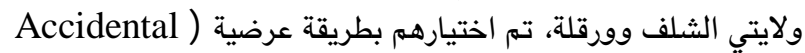

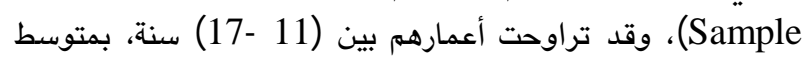

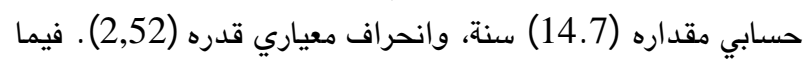

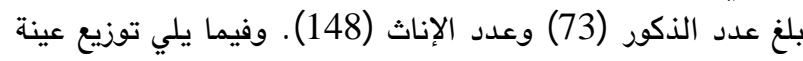
الدراسة تبعًا لمتفيري الجنس والعمر.

1. ما دلالات صدق مقياس التنمر الأخوي لدى المراهقين الذي تم

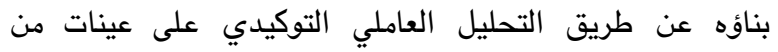

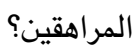

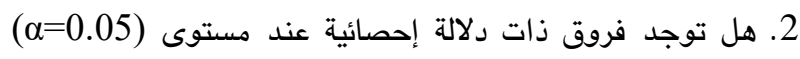
على مقياس التنمر الاخوي لدى المراهي دلالي إهين تعزى إلى الجنس

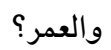

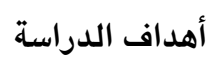

تهدف الدراسة الحالية إلى توفير أداة فعالة وصادقة لقياس

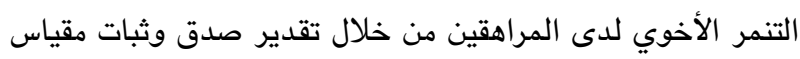

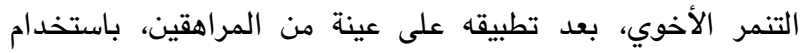

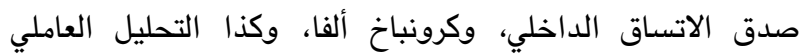

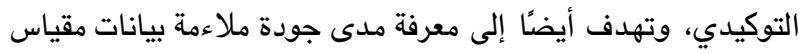

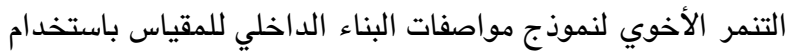

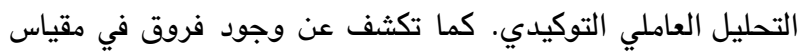
التنمر الأخوي لدى المراهقين تعزى إلى الجنس والعمر .

أهمية الدراسة

تنبع أهمية الدراسة الحالية من أهمية متفير التنمر الأخوي

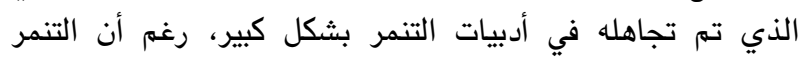

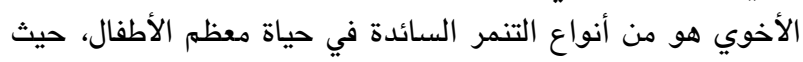

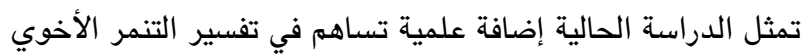
وتوفير أداة لقياسه.

كما تنبع أهمية الدراسة التطبيقية من أنها تشكل إثراءً لمجال

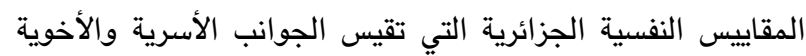

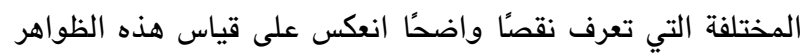

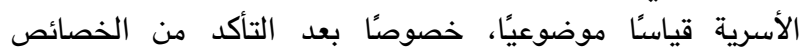

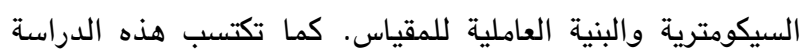

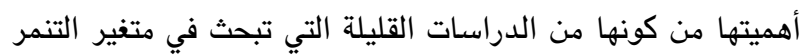

\begin{tabular}{|c|c|c|c|}
\hline النسبة المئوية (\%) & عدد الأفراد & المستوى & المتغير \\
\hline 33 & 73 & ذكور & \multirow{2}{*}{ الجنس } \\
\hline 67 & 148 & إناث & \\
\hline 39.4 & 87 & مرحلة المراهقة الأولى 11- 14 & \multirow[b]{3}{*}{ مراحل المراهقة } \\
\hline 58.8 & 130 & مرحلة المراهقة الوسطى 14-18 & \\
\hline 1.8 & 4 & مرحلة المراهقة المتأخرة 18-25 & \\
\hline
\end{tabular}

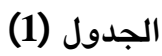

توزيع عينة الدراسة تبعا لمتغيري الجنس والعمر

المراهقة الأولى التي بلغت نسبتها (39.4\%)، فيما كانت النسبة الأقل لمرحلة المراهقة المتأخرة؛ إذ بلفت (1.8\%) (19.4).
نلاحظ من الجدول (1) أن نسبة الإناث أكبر من نسبة

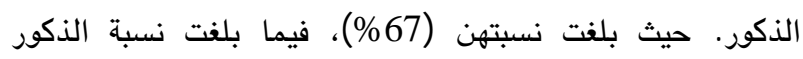

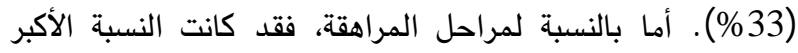

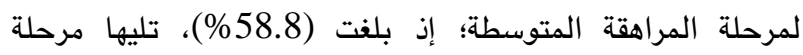


مرتفع. ويدل المتوسط الحسابي الأقل من المتوسط الفرضي على منى مستوى منخفض. وتنقسم كل صورة للمقياس إلى ثلاثة أبعاد أساسية هي:

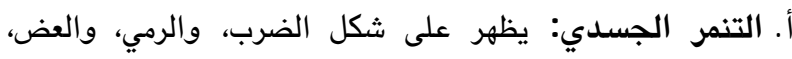

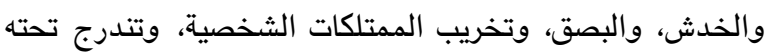

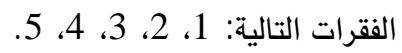
ب. التنمر العاطفي: يظهر على شكل الاستفزاز والقيام بسلوكيات جارحة للأخ كالتجاهل، وتندرج تحته الفقرات التالية: 6، 7،

ج. التنمر اللفظي: يظهر على شكل السخرية من الإخوة، والتقليل

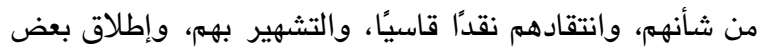

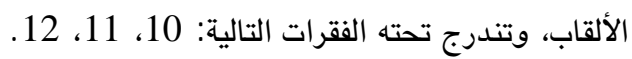

4- تم عرض المقياس على مجموعة من أساتذة علم النفس في

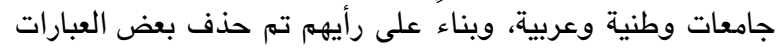

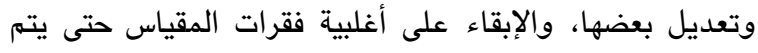
الحصول على الصورة النهائية للمقياس.

صدق وثبات المقياس بصورته الأولية: من أجل تقدير صدق

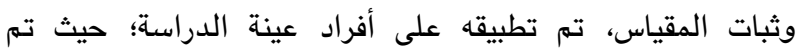

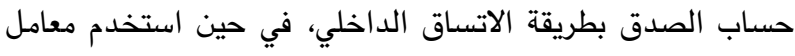

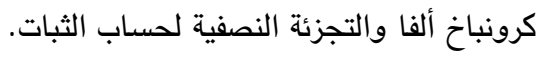

صدق الاتساق الداخلي: يقصد بالاتساق الداخلي قوة الارتباط

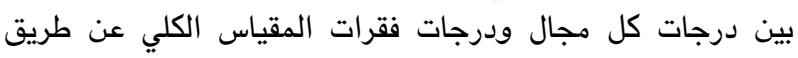

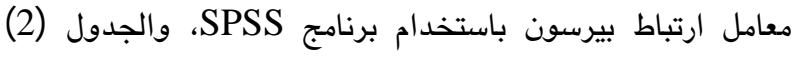
يوضح هذا الإجراء.

أداة الدراسة (مقياس التنمر الأخوي لدى المراهقين) مرّ إعداد المقياس بعدة خطوات تمثلت فيما يلي: 1- تم الاطلاع على بعض الأطر النظرية التي تناولت التنمر بصفة عامة، والتنمر الأخوي بصفة خاصة.

2- تم الاطلاع كذلك على مجموعة من المقاييس والدراسات السابقة مول التنمر بين الأقران، والتنمر الأخوي ( Bowes et al., 2014; Parris, 2013; Tanrikulu and Campbell, 2015; Tippett and Wolke, 2015; Wolke and .(Skew, 2012; Wolke et al., 2015)

3- بعد الاطلاع على الجانب النظري وبعض المقاييس المتعلقة

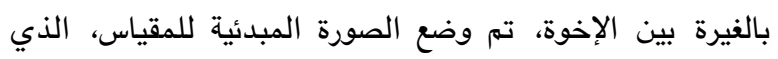

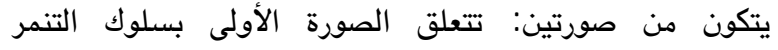

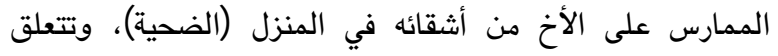

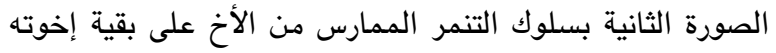

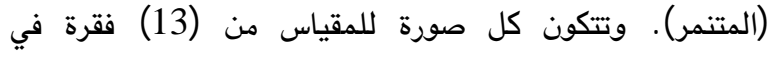

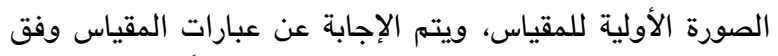
تدريجِ ليكرت الخماسي (1)

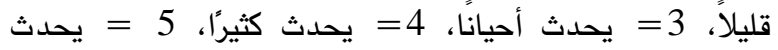
باستمرار). يتم طرح السؤال التالي: كم مرة يقوم أخوك/أختك

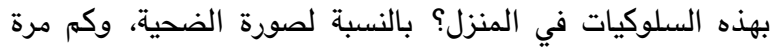

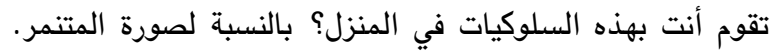

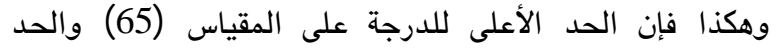

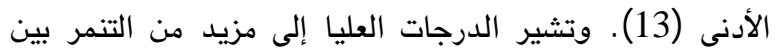

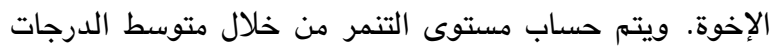

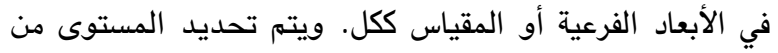

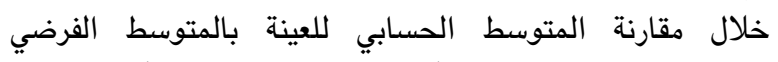

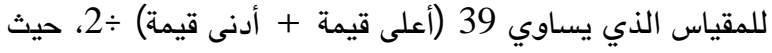
يدل المتوسط الحسابي الأكبر من المتوسط الفرضي الفي على الفي مستوى

الجدول (2)

معاملات /رتباط الفقرات مع المقياس ككل

\begin{tabular}{|c|c|c|c|c|c|c|}
\hline \multicolumn{3}{|c|}{ التعرض للتنمر من قبل الإخوة (المتنمر) } & \multicolumn{4}{|c|}{ التنمر الممارس على الإخوة (الضحية) } \\
\hline مستوى الدلالة & الارتباط & 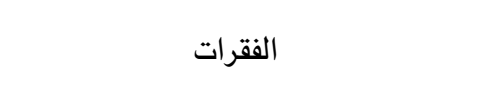 & مستوى الدلالة & الارتباط & 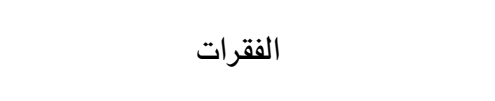 & 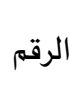 \\
\hline 0.01 & 0.530 & 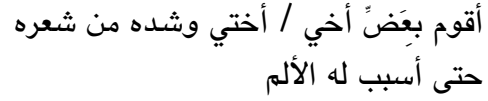 & 0.01 & 0.626 & 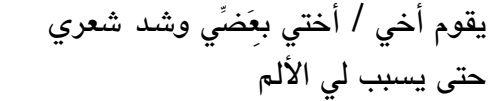 & 1 \\
\hline 0.01 & 0.654 & أفتعل أسبابًا للتشاجر مع أخي/ أختي & 0.01 & 0.781 & يفتعل أخي/ أختي أسبابًا للتشاجر معي & 2 \\
\hline 0.01 & 0.629 & أضرب أخي/ أخي وأدفعه دون مبرر & 0.01 & 0.672 & يضريني أخي/ أخي ويدفعني دون مبرر & 3 \\
\hline 0.01 & 0.532 & أعبث بالأشياء الخاصة بأخي/ أختي & 0.01 & 0.677 & يقوم أخي/ أختي بالعبث بأشيائي الخاصة & 4 \\
\hline 0.01 & 0.557 & أقوم بتهديد أخي/ أختي وإجباره على لأشياء & 0.01 & 0.600 & القيام بأشياء لا أريد فعلها أختيدي وإجباري على & 5 \\
\hline 0.01 & 0.564 & 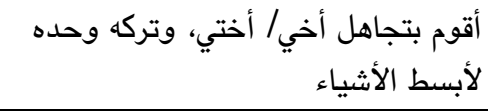 & 0.01 & 0.487 & لأبسط الأشياء أختي بتجاهلي وتركي وحدي & 6 \\
\hline
\end{tabular}




\begin{tabular}{|c|c|c|c|c|c|c|}
\hline 0.01 & 0.627 & لا أظهر اهتمامًا بوجود أخي/ أختي معي & 0.01 & 0.556 & لا يظهر أخي/ أختي اهتمامًا لوجودي معه & 7 \\
\hline 0.01 & 0.613 & أقوم باستفزاز أخي / أختي بطريقة جارحة & 0.01 & 0.636 & يقوم أخي / أختي باستفزازي بطريقة & 8 \\
\hline 0.01 & 0.541 & أخي/ أختم بإتلاف أشياء لها قيمة عاطفية لدى & 0.01 & 0.592 & عاطفية لدي أخي/ أختي بإتلاف أشياء لها قيمة & 9 \\
\hline 0.01 & 0.727 & ألطلق على أخي / أختي ألقابا سيئة & 0.01 & 0.625 & للسخرية ملي أخي / أختي ألقابا سيئة & 10 \\
\hline 0.01 & 0.501 & أخي/ أختي لجعلاق أكاذيب وإشاعات حول يكرهونه & 0.01 & 0.602 & يقوم أخي/ أختي باختلاق أكاذيب & 11 \\
\hline 0.01 & 0.570 & أقول أشياء وقحة عن أخي/أختي أمام & 0.01 & 0.527 & الآخرين أخي/ أختي أشياء وقحة عني أمام & 12 \\
\hline 0.01 & 0.589 & 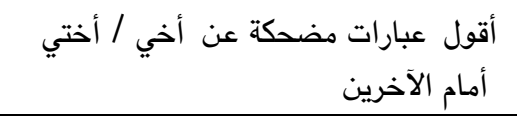 & 0.01 & 0.605 & يقول أخي / أختي عبارات مضحكة عني & 13 \\
\hline
\end{tabular}

يلاحظ من الجدول (2) أن معاملات ارتباط الفقرات مع المقياس ككل دالة إحصائًاً عند مستوى الدلالة 0.01.

ارتباط الأبعاد الأساسية مع المقياس ككل

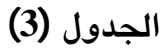

معاملات /رتباط الأبعاد الأساسية مع المقياس ككل

\begin{tabular}{|c|c|c|c|c|c|}
\hline \multicolumn{3}{|c|}{ التعرض للتنمر من قبل الإخوة (المتنم) } & \multicolumn{3}{|c|}{ التنمر الممارس على الإخوة (الضحية) } \\
\hline مستوى الدلالة & معامل الارتباط & 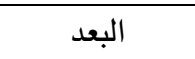 & مستوى الدلالة & معامل الارتباط & البعد \\
\hline 0.01 & 0.835 & التنمر الجسمي & 0.01 & 0.880 & التنمر الجسدي \\
\hline 0.01 & 0.819 & التنمر العاطفي & 0.01 & 0.794 & التنمر العاطفي \\
\hline 0.01 & 0.795 & التنمر اللفظي & 0.01 & 0.781 & التنمر اللفظي \\
\hline
\end{tabular}

أما بالنسبة لصورة التعرض للتنمر من الإخوة (المتنمر)، فقد

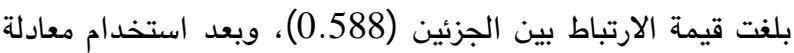

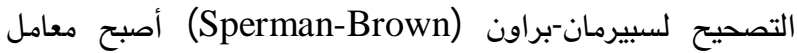
الثبات (0.741)، فيما بلغت قيمة معامل الثبات بمعادلة تصحيح جوتمان (0.716). (0.74)،

وباعتبار معاملات الصدق والثبات لمقياسِ التنمر الأخوي

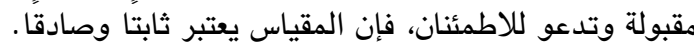

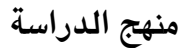

تم استخدام المنهج الوصفي من خلال بناء مقياس للتنمر الأخوي والتأكد من البنية العاملية للمقياس عن طريق التحليل

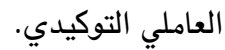
النتائج أولاً: عرض نتائج السؤال الأول: ما دلالت صدق مقياس التنمر

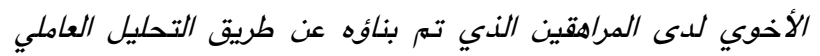

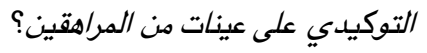
للإجابة عن هذا السؤال، تم اتباع الإجراءات الآتية:
يلاحظ من الجدول أن معاملات ارتباط كل الأبعاد الأساسية

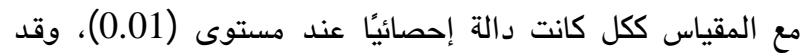
تراوحت معاملات الارتباط بين (0.781-0.880). وهي معاملات

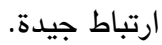
ثبات المقياس

تم حساب ثبات الاتساق الداخلي عن طريق " كرونباخ ألفا " وعن طريق التجزئة النصفية. - الاتساق الداخلي عن طريق كرونباخ ألفا: بلغت قيمته بالنسبة

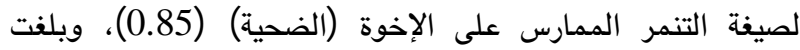
(0.83) بالنسبة لصيغة التعرض للتنمر من قبل الإخوة (المتنمر) . - الثبات عن طريق التجزئة النصفية: تم حساب الثبات أيضًا عن التصات

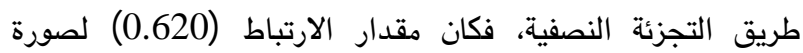
التنمر الممارس على الإخوة (الضحية)، وبعد استخدام معادلة لإنة

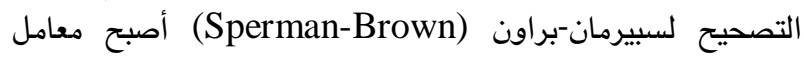
الثبات (0.766)، فيما بلفت قيمة معامل الثبات بمعادلة تصحيح

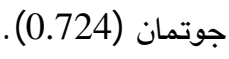




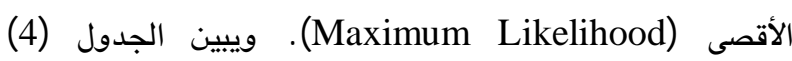

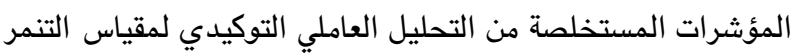

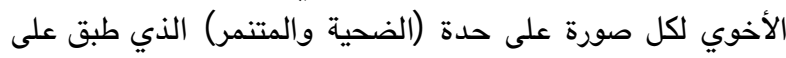

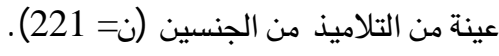

فحصت الدراسة الحالية الصدق البنائي لمقياس التنمر الأخوي التيدي التئي باستخدام أسلوب التحليل العاملي التوكيدي من المستوى التئي الثاني عن (Second-order Confirmatory Factor Analysis) طريق برنامج (AMOS24)، وقد تم استخدام طريقة الاحتمال أولاً: صورة التنمر الأخوي الممارس على الإخوة

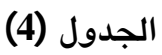

مؤشرات المطابقة للنموذج: صورة التنمر الممارس على الإخوة (الضحية)

\begin{tabular}{|c|c|c|}
\hline التقدير & ق ق المؤشر & مؤشرات حسن المطابقة \\
\hline يحب أن يكون غير دال & 94.609 & مربع كاي \\
\hline يساوي أو أكبر من 0.90 لقبول المطابقة & 0.951 & مؤشر المطابقة المقارن CFI \\
\hline يساوي أو أكبر من 0.90 & 0.935 & مؤشر حسن المطابقة GFI \\
\hline أقل من 0.06 & 0.06 & مؤشر جذر متوسط مريع خطأ التقريب RMSEA \\
\hline
\end{tabular}

جذر متوسط مربع خطأ التقريب (RMSEA)، الذي يعد من أهم تشير نتائج مؤشرات جودة المطابقة عمومًا إلى أنها كلها

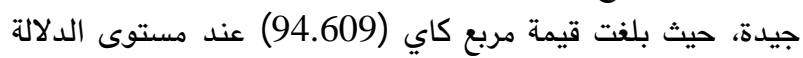

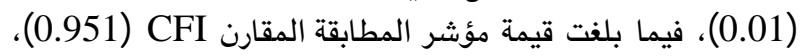

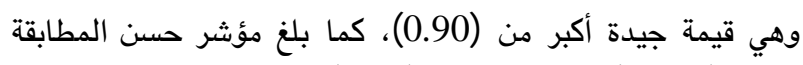
(0.935) GFI

(1) الشكل تشبعات مقياس التنمر الأخوي: صورة التنمر الممارس على الإخوة (الضحية) في صورته النهائية بعد التعديل من خلال التحليل العاملي التوكيدي

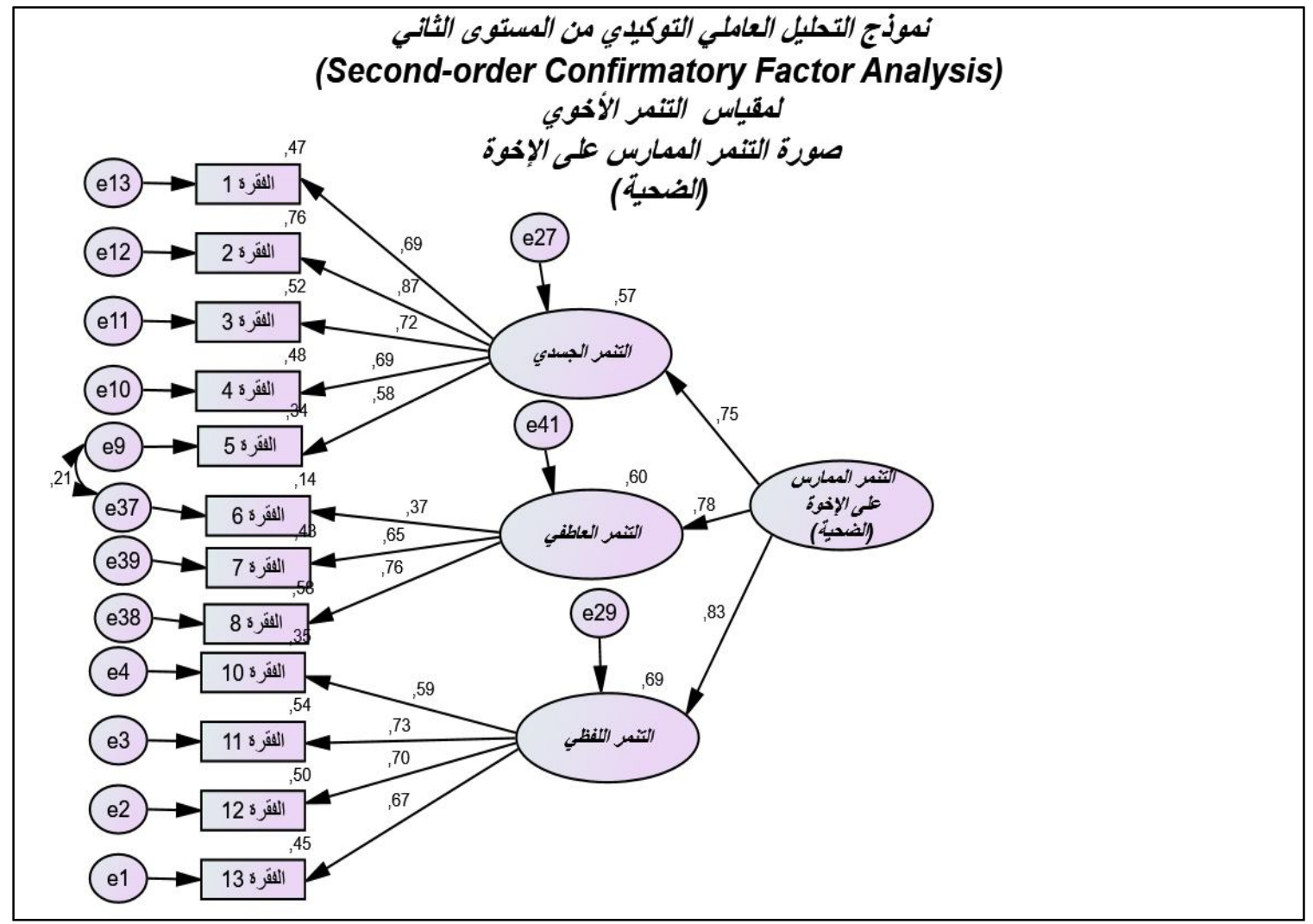


عدد فقرات المقياس في صورته النهائية بعد التحليل العاملي

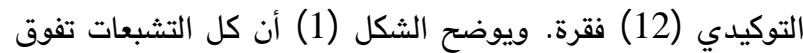

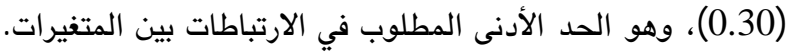

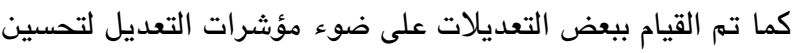

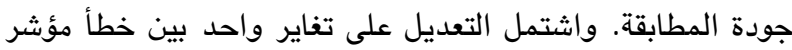
الفقرة (5) والفقرة (6).
يوضح الثكل (1) درجة تشبع الفقرات على الأبعاد الفرعية

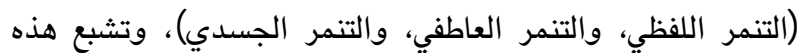

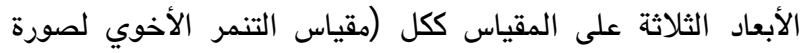

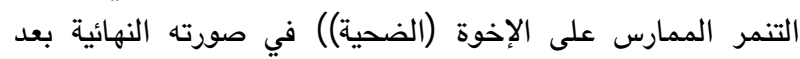

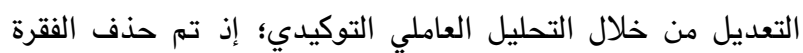

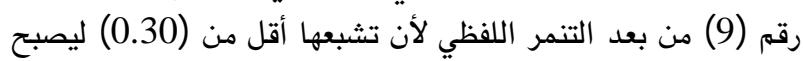

ثانيًا: صورة التنمر الأخوي من قبل الإخوة (المتنمر)

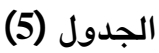

مؤشرات المطابقة للنموذج: صورة التنمر الأخوي من قبل الإخوة (المتنمر)

\begin{tabular}{|c|c|c|}
\hline 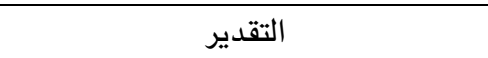 & قيمة المؤشر & مؤشرات حسن المطابقة \\
\hline يحب أن يكون غير دال & 145.325 & مربع كاي \\
\hline يساوي أو أكبر من 0.90 لقبول المطابقة & 0.880 & مؤشر المطابقة المقارن CFI \\
\hline يساوي أو أكبر من 0.90 & 0.904 & GFI مؤشر حسن المطابقة \\
\hline أقل من 0.06 & 0.09 & مؤشر جذر متوسط مربع خطأ التقريب RMSEA \\
\hline
\end{tabular}

يتعلق بمؤشر جذر متوسط مربع خطأ التقريب (RMSEA) فقد وهن تشير نتائج مؤشرات جودة المطابقة عمومًا إلى أنها كلها بلغ (0.09)، وهي قيمة مقبولة، مما يدل على ندون نجاح النموذج. جيدة، حيث بلغت قيمة مريع كاي (145.325) عند مستوى الدلالة

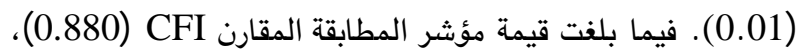

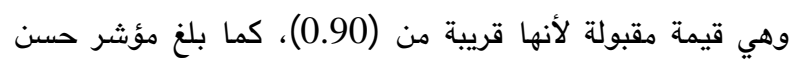

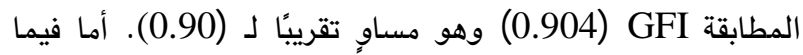

(2) (2) (2)
والشكل (2) يبين تشبعات مقياس التنمر الأخوي: صورة التنمر الأخوي من الإخوة (المتنمر) في صورته النهائية بعد لتعدين

تشبعات مقياس التنمر الأخوي: صورة التنمر الأخوي من الإخوة (المتنمر) في صورته النهائية بعد التعديل من خلال التحليل العاملي التوكيدي

\section{نموزج التحليل العاملي التوكيإي من المستوى الثانسي}

(Second-order Confirmatory Factor Analysis)

لمقياس التنمر الأخوي

صورة التعرض للتنمر من قبل الإخوة الإخد

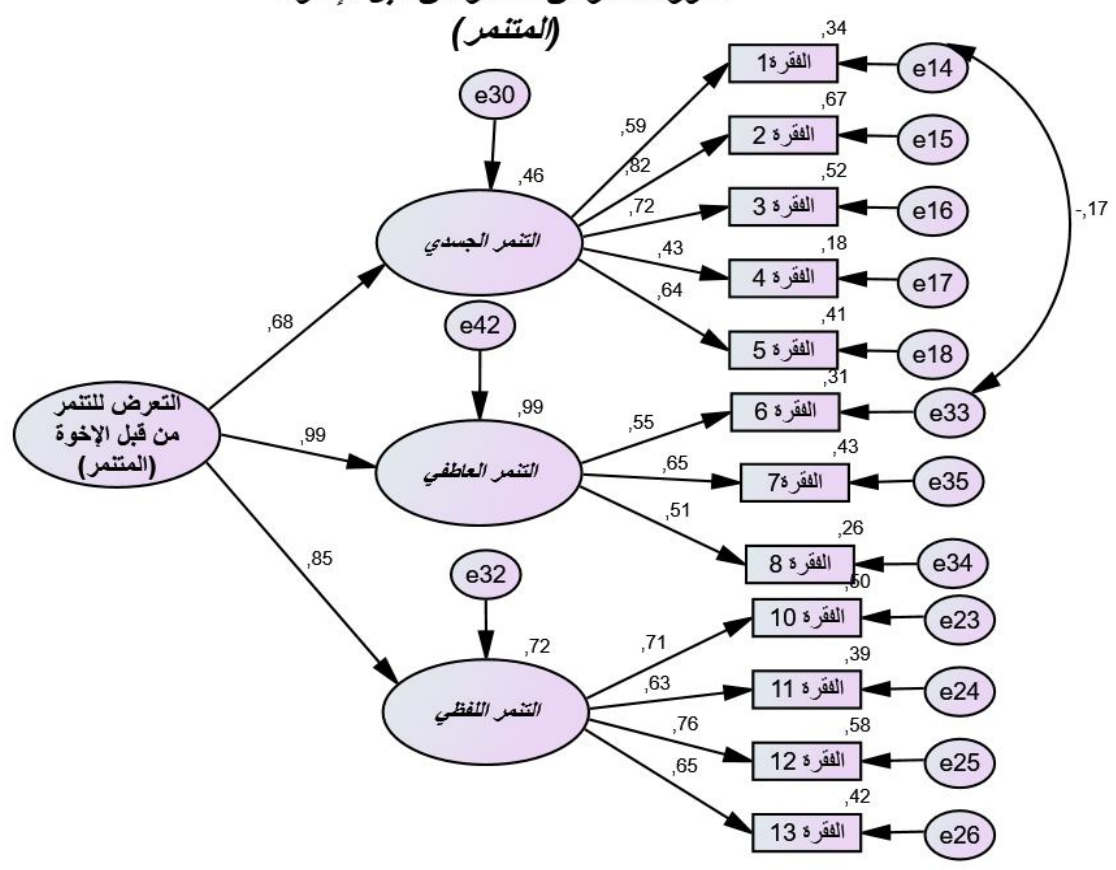


ليصبح عدد فقرات المقياس في صورته النهائية بعد التحليل العاملي

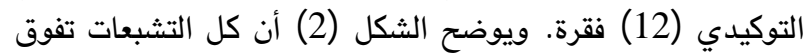
(0.30)، وهو الحد الأدنى المطلوب في الارتباطات بين المتغيرات.

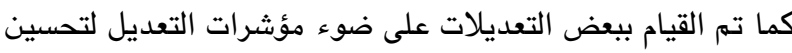
جودة المطابقة، اشتملت على تغاير واحد بين خطأ مؤشر الفقرة 1 بون

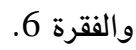

يوضح الثكل (2) درجة تشبع الفقرات على الأبعاد الفرعية

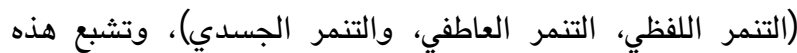

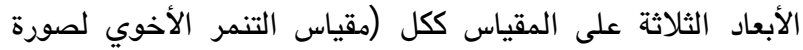
التنمر الممارس من (قبل الإخوة (المتنمر))؛ في صورته النهاب النهائية

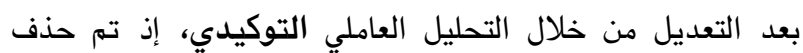
الفقرة (9) من بعد التنمر اللفظي لأن تشبعها أقل من التعل (0.30)،

الصدق التقاربي (Convergent Validity)

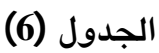

\begin{tabular}{|c|c|c|c|c|}
\hline \multicolumn{2}{|c|}{ التعرض للتنمر من الإخوة (المتنمر) } & \multicolumn{3}{|c|}{ التنمر الممارس على الإخوة (الضحية) } \\
\hline 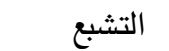 & 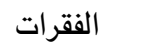 & 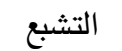 & 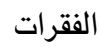 & 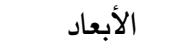 \\
\hline 0.586 & 1 & 0.689 & 1 & \multirow{5}{*}{ التنمر الجسدي } \\
\hline 0.8160 & 2 & 0.8740 & 2 & \\
\hline 0.7210 & 3 & 0.7210 & 3 & \\
\hline 0.4290 & 4 & 0.6910 & 4 & \\
\hline 0.6390 & 5 & 0.5810 & 5 & \\
\hline 0.5530 & 6 & 0.3710 & 6 & \multirow{3}{*}{ التنمر العاطفي } \\
\hline 0.6530 & 7 & 0.6530 & 7 & \\
\hline 0.5080 & 8 & 0.7610 & 8 & \\
\hline 0.7070 & 10 & 0.5930 & 10 & \multirow{4}{*}{ التنمر اللفظي } \\
\hline 0.6260 & 11 & 0.7340 & 11 & \\
\hline 0.7600 & 12 & 0.7050 & 12 & \\
\hline 0.646 & 13 & 0.669 & 13 & \\
\hline
\end{tabular}

الثبات عن طريق ألفا كرونباخ

بلفت قيمة ألفا (0.844) بالنسبة لمقياس التنمر الأخوي:

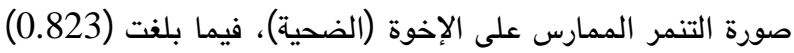

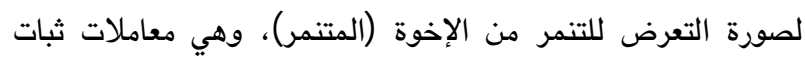

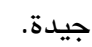
الثبات المركب (Composite Reliability): تم حساب الثبات

المركب لنموذج الدراسة وفق المعادلة الآتية (Kline, 2015):

$\mathbf{C} \mathbf{R}=\frac{(\text { Sum of loading })^{2}}{{\text { (Sum of loading })^{2}+\text { Sum of Indicator Measurement Error }}^{2}}$

Indicator Measurement Error calculated by 1 SMC (Squared Multiple Correlation)

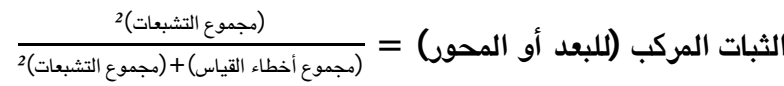
(Laoun, 2016)
يلاحظ من الجدول (6) تحقق الصدق التقاربي الذي يفترض الصف

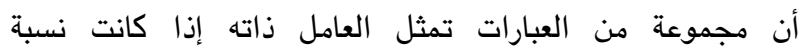

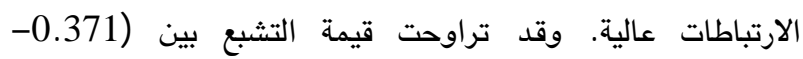

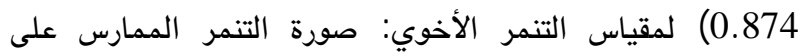

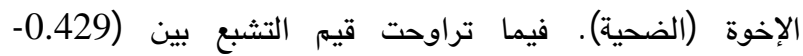

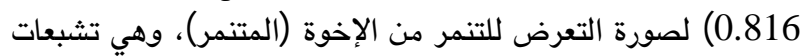

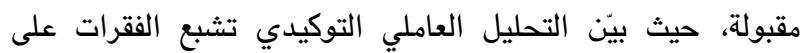
العامل أو البعد الذي تنتمي إليه، مع أخذ مؤشرات المطابقة أيضًا

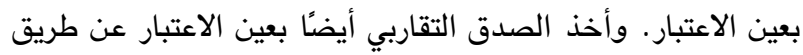

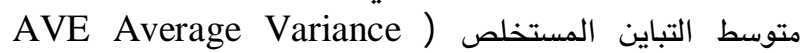
(Extracted

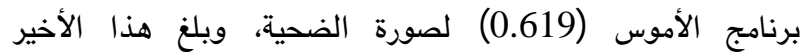
(0.724) لصورة التنمر من الإخوة (المتنمر)، وكل منهما معاملات جيدة تشير إلى أن النموذج يتمتع بصدق مقبول. 


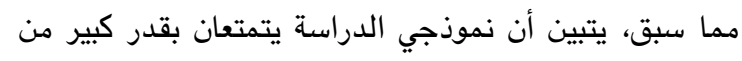

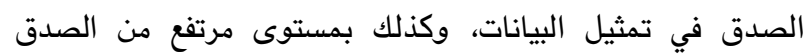

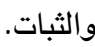

عرض نتائج السؤال الثاني: هل توجد فروق ذات دلالة إحصائية

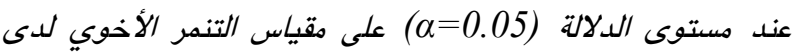
المراهقين تعزى إلى الجنس والعمر؟ أوئا: الفروق تبعًا لمتفير الجنس

للإجابة عن هذا السؤال، تم استخدام اختبار(ت) للفرق بين

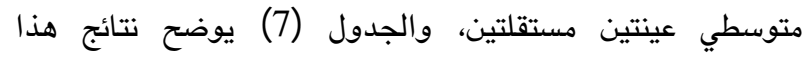

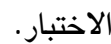

وبالتعويض في المعادلة السابقة، كانت قيمة معامل الثبات

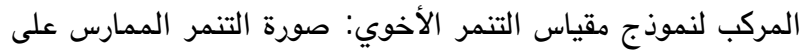

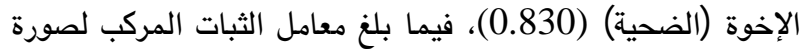
التعرض للتنمر من الإخوة (المتنمر) (0.830)، فيما (0.85)، وهي معاملات ثبات المركي لورة

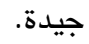

الثبات عن طريق أوميفا الموزونة

تم حساب أوميغا الموزونة عن طريق البرنامج الإحصائي

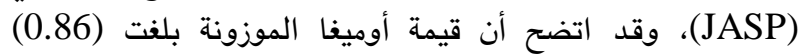

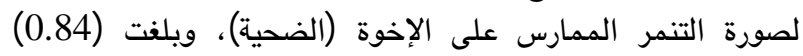

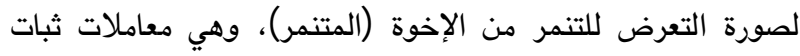

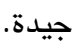

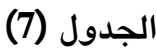

نتائج اختبار(ت) لمقارنة الفروق في التنمر الأخوي لدى المراهقين تبعا لمتغير الجنس

\begin{tabular}{|c|c|c|c|c|}
\hline مستوى الدلالة & قيمة (ت) & \multicolumn{2}{|c|}{ المتوسط الحسابي } & المتغير \\
\hline 0.01 & -2.435 & $\begin{array}{l}22.8209 \\
26.4066\end{array}$ & الإناث & صورة الأخ الضحية \\
\hline أكبر من 0.05 & -0.955 & $\begin{array}{l}19.8447 \\
20.9328\end{array}$ & الإلكور & صورة الأخ المتنمر \\
\hline
\end{tabular}

ثانيًا: الفروق تبعا لمتفير العمر

للإجابة عن هذا السؤال، تم استخدام تحليل التباين كما في

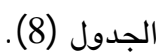

يتضح من الجدول (7) أن قيمة (ت) قد بلغت (2.435-)

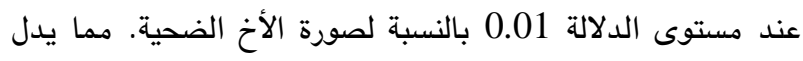

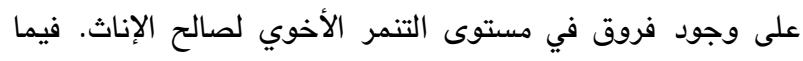

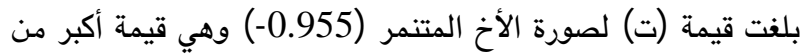

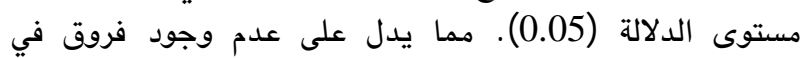
مستوى التنمر الأخوي بين الذكور والإناث.

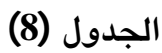

تحليل التباين البسيط للمقارنة بين المجموعات (F-test) لحساب الفروق بين متوسطات إجابات عينة الدراسة على مقياس التنمر الأخوي

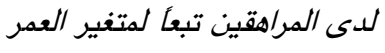

\begin{tabular}{|c|c|c|c|c|}
\hline مستوى الدلالة & النسبة الفائية & متوسط مجموع المربعات & مصدر التباين & \\
\hline \multirow{3}{*}{0.05} & \multirow{3}{*}{3.443} & 730.080 & بين المجموعات & \multirow{3}{*}{ صورة الأخ الضحية } \\
\hline & & 23110.875 & داخل المجموعات & \\
\hline & & 23840.956 & الكلي & \\
\hline \multirow{3}{*}{0.05} & \multirow{3}{*}{3.792} & 469.155 & بين المجموعات & \multirow{3}{*}{ صورة الأخ المتنمر } \\
\hline & & 13484.182 & داخل المجموعات & \\
\hline & & 13953.337 & الكلى & \\
\hline
\end{tabular}


ولتحديد اتجاه فروق التنمر الأخوي لدى المراهقين، تم

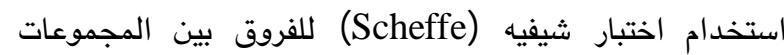

للمقارنة، كما في الجدول رقم (9) .

يشير الجدول إلى أن قيمة (ف) قد بلفت (3.443) عند

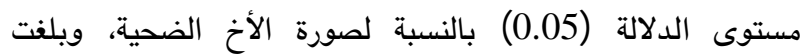

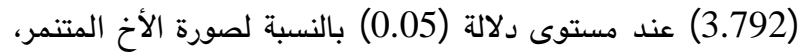

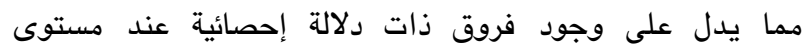

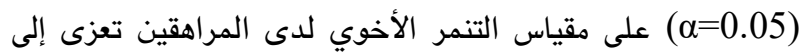

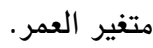

(9) - الجدول

نتائج اختبار شيفيه (Scheffe) للفروق بين المجموعات

\begin{tabular}{|c|c|c|c|}
\hline الدلالة الاحصائية & الفروق بين المتوسطات & المجموعات & المتغير \\
\hline 0.0340 & 3.73281 & المراهقة الوسطى & \multirow{6}{*}{ صورة الأخ الضحية } \\
\hline 0.8290 & 3.22638 & المراهقة المتأخرة & \\
\hline 0.0340 & -3.73281 & المراهقة الوسطى & \\
\hline 0.9950 & $.506430-$ & المراهقة المتأخرة & \\
\hline 0.8290 & -3.22638 & المراهقة المتأخرة & \\
\hline 0.9950 & 0.506430 & المراهقة المتوسطة & \\
\hline 0.0250 & 2.97735 & المراهقة الوسطى & \multirow{6}{*}{ صورة الأخ المتنمر } \\
\hline 0.7390 & 3.13143 & المراهقة المتأخرة & \\
\hline 0.0250 & -2.97735 & المراهقة الوسطى & \\
\hline 0.9990 & 0.154080 & المراهقة المتأخرة & \\
\hline 0.7390 & -3.13143 & المراهقة المتأخرة & \\
\hline 0.9990 & $0.154080-$ & المراهقة المتوسطة & \\
\hline
\end{tabular}

التي أُستعرضت آنفاً، يلاحظ أن المقياس قد صمم ليقيس صورتين

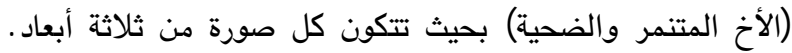

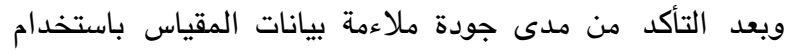

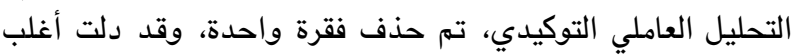

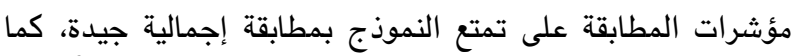

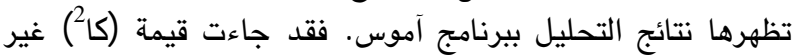
دالة لكل من النموذجين. ويعد الاختبار الأخير مقياسًا أساسيًا

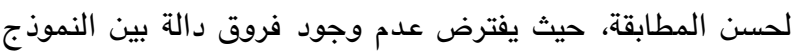

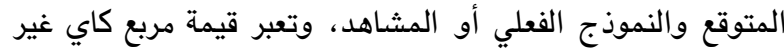

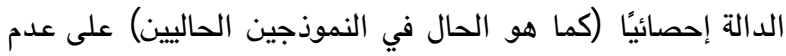

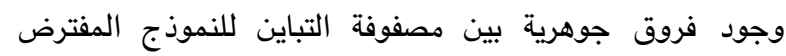
ومصفوفة التباين للعينة.

ويعاب على هذا المعامل تأثره في دلالة قيمته بحجم العينة

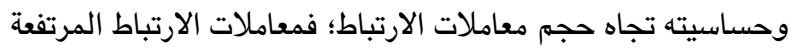

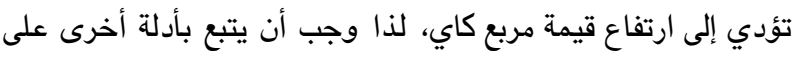

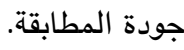

يلاحظ من الجدول أن هناك فروقًا في التنمر بين المراهقة

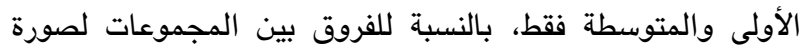

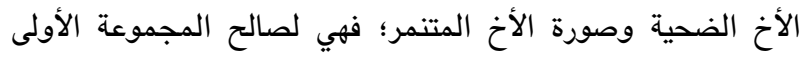

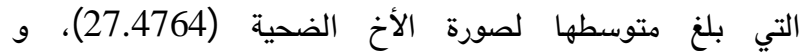
(22.3814) لصورة الأخ المتنمر.

مناقشة النتائج

أشارت نتائج الدراسة المتعلقة بالخصائص السيكومترية

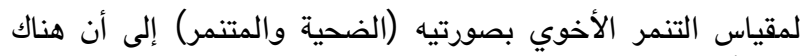

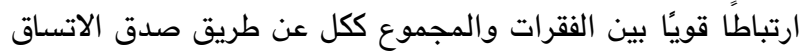

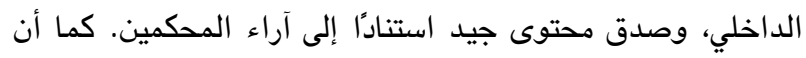

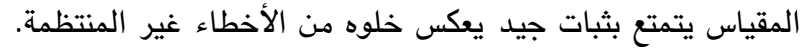
وأنه يقيس المقدار الحقيقي للسمة التي يهدف لقياسها؛ أي التنمر الأخوي.

كما هدفت الدراسة إلى معرفة مدى جودة ملاءمة بيانات مقياس

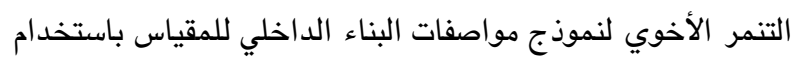
التحليل العاملي التوكيدي على البيئة الجزائرية. ومن خلال التواء النتائج 


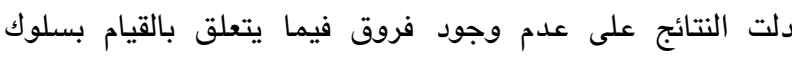

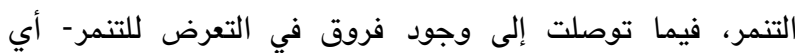
الضحية؛ إذ أبلغت الإناث أنهن أكثر تعرضًا للتنمر مقارنة بالذكور .

وتتعارض هذه النتائج مع النتائج التي تم التوصل إليها فيما

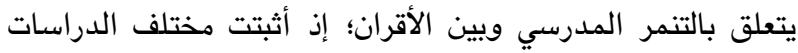

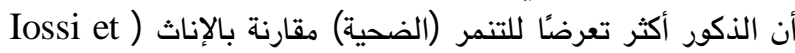

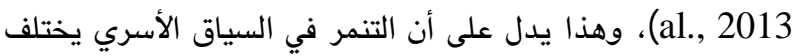

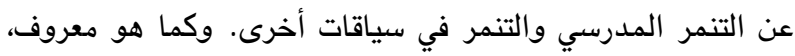

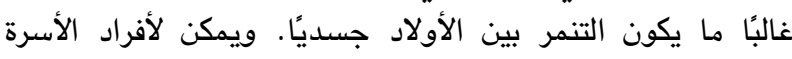

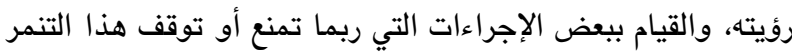

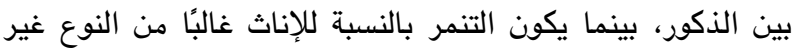

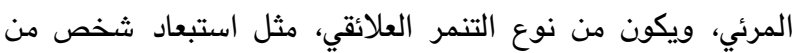

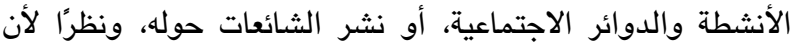

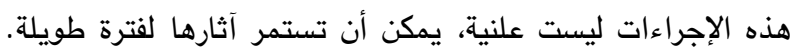
وفيما يتعلق بالتنمر على بقية الإخوة، كان مستوى التئ التنمر متقاربًا

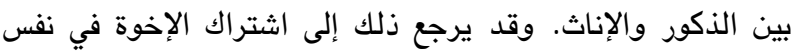

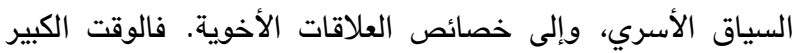

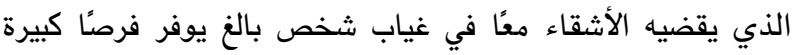

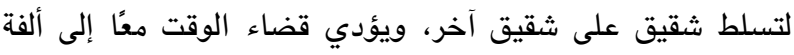

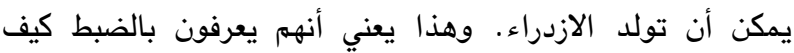
يثيرون أو يزعجون بعضهم البعض، وهذا ولداء يجعل أدوار التنمر قابلة

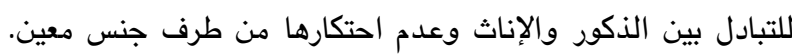

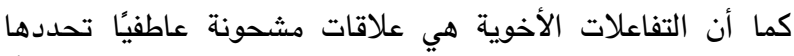
العواطف القوية غير المقيدة للجودة الإيجابية والسلبية وأحيانًا

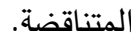

وبالنسبة لعامل السن ودوره في التنمر الأسري، بينت الدراسة

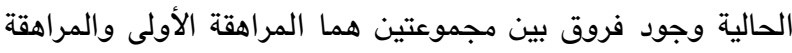

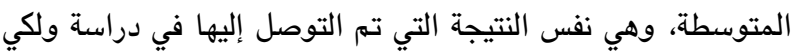

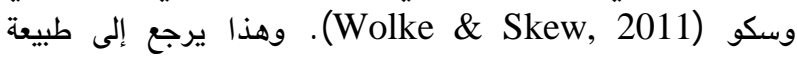

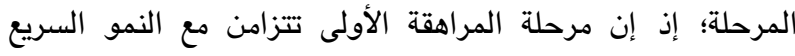

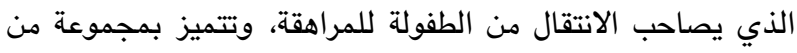

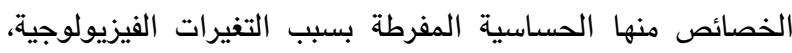

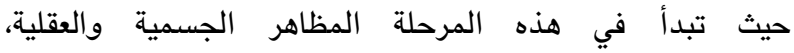

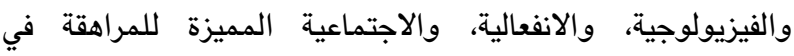

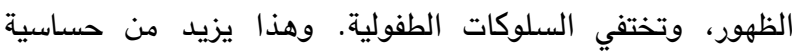

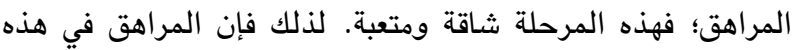

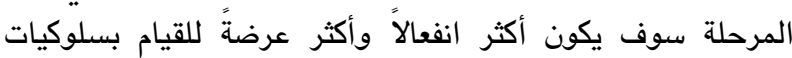

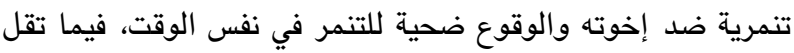

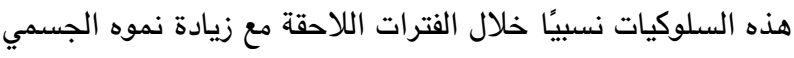

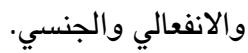

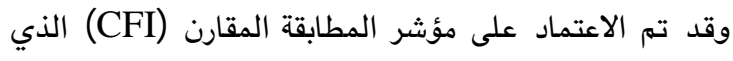

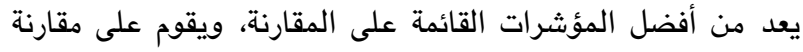

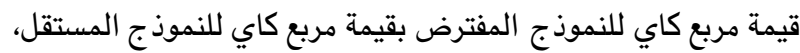

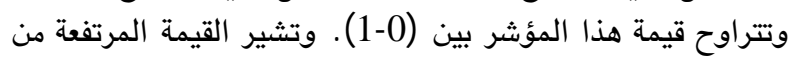

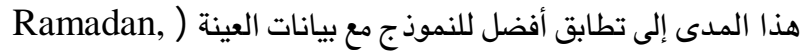

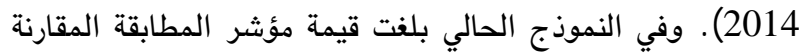

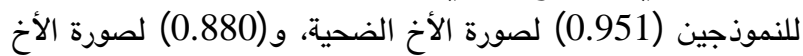
المتنمر، وكل من القيمتين عالية. الأولى تفوق (0.90) والثية والثانية الثانية

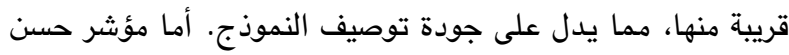
المطابقة (Goodness of Fit Index: GFI) فهو يقيس مقدار

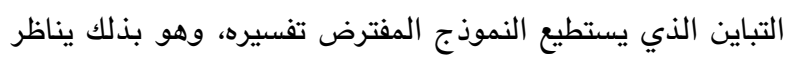

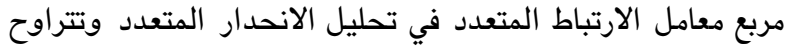

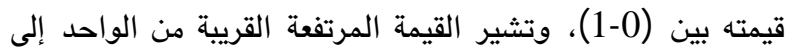

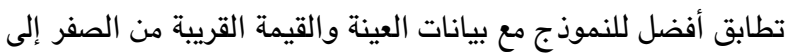

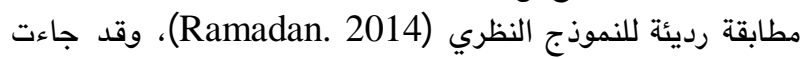

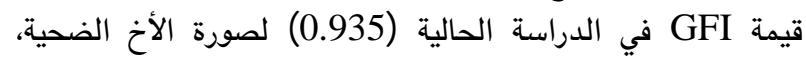

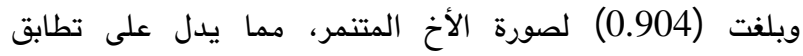

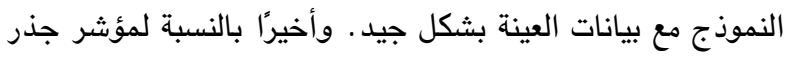

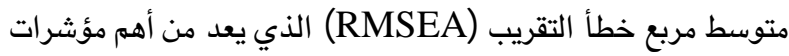

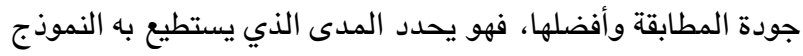

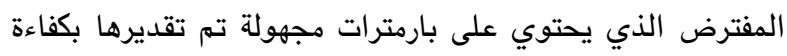
تحقيق مطابقة مع مصفوفة التباين والتغاير للعينة عند توفرها. ويقيس مؤشر (RMSEA) التباعد عن طريق درجات الحرية مما

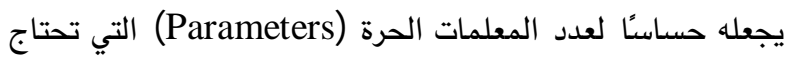

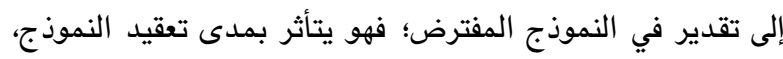

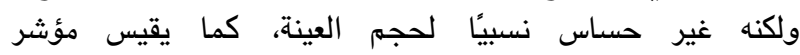
المدى الذي يعد فيه النموذج ملائمًا بشكل منطقي العينة (RMSEA)

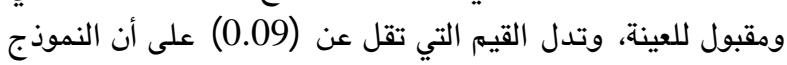

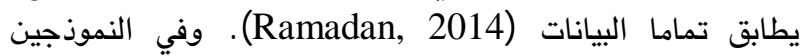

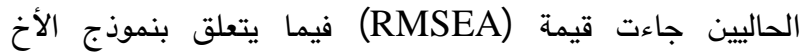
الضحية (0.06)، أما في نموذج الأخ المتنمر فبلغت (0.09). وهما قيمتان جيدتان، مما يدل على أن النموذج يطابق تمامًا

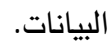

تم التوصل أيضًا إلى وجود فروق في مستوى التنمر الأخوي

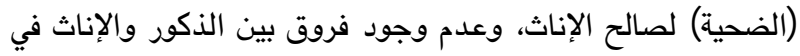

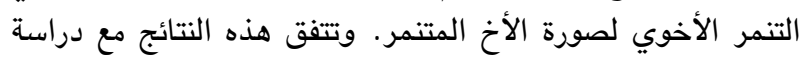

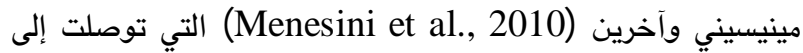

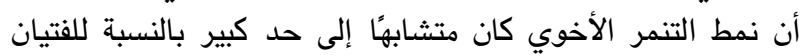
والفتيات، ودراسة دنكان (Duncan, 1999) التي توصلت إلى الى أنه

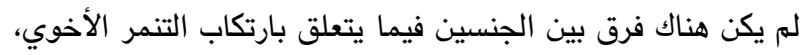

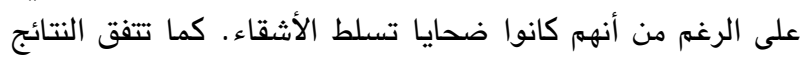

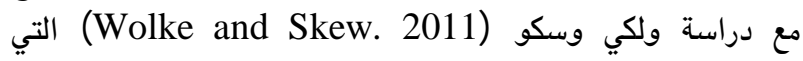
توصلت إلى أن الأولاد في أغلب الأحيان كانوا متنمرين أو ضحايا

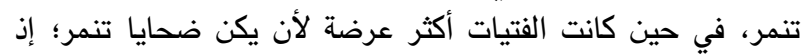




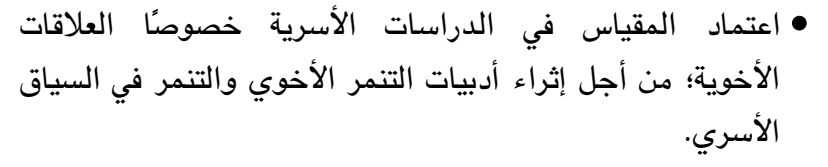

• إجراء بحوث للوقوف على مصادر التنمر الأخوي وسبل الوقاية
في ضوء النتائج التي تم التوصل إليها، يمكن إدراج التوصيات

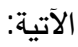

• تدعيم نتائج بناء المقياس والتحقق من بنيته العاملية بإجراء ألتاء دراسات على نفس المقياس، أو بناء مقاييس أخرى تقيس التنمر

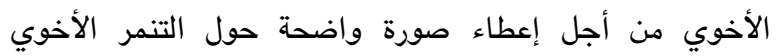
والسمات المكونة له ومدى تطابقه أو اختلافه مع تنمر الأقران.

• التأكد من الخصائص السيكومترية للمقياس بطرق أخرى عن

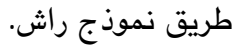

\section{References}

Abdul Majeed, M. A., \& Hassan, D. S. (2017). School bullying and its relation with movement abilities Modern Sport Journal, 16(4), 121-132 .

Adams, F. D., \& Lawrence, G. J. (2011). Bullying victims: The effects last into college. American Secondary Education, 40(1) 4-13 .

Al-Raqqad, H. K., Al-Bourini, E. S., Al Talahin, F. M., \& Aranki, R. M. (2017). The impact of school bullying on students' academic achievement from teachers' point of view. International Education Studies, 10(6), 44-50 .

Badarneh, L. K. (2012). Sources of social support and its relationship with bullying behavior among adolescents. Master's Thesis, Amman Arab University, Jordan .

Bender, D., \& Lösel, F. (2011). Bullying at school as a predictor of delinquency, violence and other anti-social behaviours in adulthood. Criminal Behaviour and Mental Health, 21(2), 99-106 .

Bowes, L., Wolke, D., Joinson, C., Lereya, S. T., \& Lewis, G. (2014). Sibling bullying and risk of depression, anxiety and self-harm: A prospective cohort study. Pediatrics , 134 (4) , e1032-e1039 .

Dijkstra, J. K., Lindenberg, S., \& Veenstra, R. (2008). Beyond the class norm: Bullying behavior of popular adolescents and its relation to peer acceptance and rejection. Journal of Abnormal Child Psychology, 36(8), 1289 .
Dill, E. J., Vernberg, E. M., Fonagy, P., Twemlow, S. W., \& Gamm, B. K. (2004). Negative effects in victimized children: The roles of social withdrawal, peer rejection and attitudes toward bullying. Journal of Abnormal Child Psychology, 32(2), 159-173 .

Duncan, R .D. (1999). Peer and sibling aggression: An investigation of intra-and extra-familial bullying. Journal of Interpersonal Violence, 14(8), 871-886 .

Finkelhor, D., Turner, H., \& Ormrod, R. (2006). Kid's stuff: The nature and impact of peer and sibling violence on younger and older children. Child Abuse \& Neglect, 30(12), 1401-1421 .

Harel-Fisch, Y., Walsh, S. D., Fogel-Grinvald, H., Amitai, G., Pickett, W., Molcho, M.,...,\& Craig, W. (2011). Negative school perceptions and involvement in school bullying: A universal relationship across 40 countries. Journal of Adolescence, 34(4), 639-652 .

Hoetger, L. A., Hazen, K. P., \& Brank, E. M. (2015). All in the family: A retrospective study comparing sibling bullying and peer bullying. Journal of Family Violence, 30(1), 103-111.

Iossi Silva, M. A., Pereira, B., Mendonça, D., Nunes, B., \& Oliveira, W. A. D. (2013). The involvement of girls and boys with bullying: An analysis of gender differences. International Journal of Environmental Research and Public Health, 10(12), 68206831. 
Kandemir Özdinç, N. (2019). Sibling bullying and peer bullying relations to empathy, moral disengagament, problem solving and parental acceptance-rejection. Doctoral Dissertation, METU-Middle East Technical University.

Kline, R. B .(2015) .Principles and practice of structural equation modeling. Guilford Publications.

Laoun, A. (2016). Organizational confidence and its relationship to the organizational commitment of civil protection workers in the Wilayat of Djelfa. Master Thesis, University of Oran 2, Algeria .

Menesini, E., \& Camodeca, M. (2008). Shame and guilt as behaviour regulators: Relationships with bullying, victimization and prosocial behaviour. British Journal of Developmental Psychology, 26(2), 183-196.

Menesini, E., Camodeca, M., \& Nocentini, A. (2010). Bullying among siblings: The role of personality and relational variables. British Journal of Developmental Psychology, 28(4), 921-939.

Naylor, P. B., Petch, L., \& Williams, J. V. (2011). Sibling abuse and bullying in childhood and adolescence: Knowns and unknowns. Children Behaving Badly?: Peer Violence between Children and Young People, 31, 47-57.

Olweus, D. (1978). Aggression in the schools: Bullies and whipping boys. Oxford, England: Hemisphere.

Olweus, D. (1993). Bullying at school: What we know and what we can do. Malden, MA: Blackwell Publishing.

Olweus D. (1996). The revised olweus ully/victim questionnaire. Bergen: Research Center for Health Promotion.

Olweus, D., \& Limber, S. P. (2010). Bullying in school: Evaluation and dissemination of the Olweus bullying prevention program. American Journal of Orthopsychiatry, 80(1), 124-134.

Parris, L. N. (2013). The development and application of the coping with bullying scale for children .Doctoral Thesis, Georgia State University.
Radford, L., Corral, S., Bradley, C., \& Fisher, H. L. (2013). The prevalence and impact of child maltreatment and other types of victimization in the UK: Findings from a population survey of caregivers, children and young people and young adults. Child Abuse \& Neglect, 37(10), 801-813 .

Ramadan, M. A. (2014). Factorial structure of the cognitive abilities test "CogAT"by using exploratory and confirmatory factor analysis. Master Thesis, University of Damascus, Syria .

Skinner, J. A., \& Kowalski, R. M. (2013). Profiles of sibling bullying. Journal of Interpersonal Violence, 28(8), 1726-1736 .

Tanrikulu, I., \& Campbell, M. A. (2015). Sibling bullying perpetration: Associations with gender, grade, peer perpetration, trait anger and moral disengagement. Journal of Interpersonal Violence, 30(6), 1010-1024.

Tippett, N., \& Wolke, D. (2015). Aggression between siblings: Associations with the home environment and peer bullying. Aggressive Behavior, 41(1), 14-24 .

Vassallo, S., Edwards, B., Renda, J., \& Olsson, C. A. (2014). Bullying in early adolescence and antisocial behavior and depression six years later: What are the protective factors? Journal of School Violence, 13(1), 100-124 .

Vespo, J. E., Pedersen, J., \& Hay, D. F. (1995). Young children's conflicts with peers and siblings: Gender effects. Child Study Journal, 25(3), 189-212.

Wolke, D., \& Skew, A. J. (2011). Bullied at home and at school: Relationship to behaviour problems \& unhappiness, understanding society. Institute for Social and Economic Research, Essex: Understanding Society. (Understanding Society: Early findings from the first wave of the UK's household longitudinal study).

Wolke, D., \& Skew, A. J. (2012). Bullying among siblings. International Journal of Adolescent Medicine and Health, 24(1), 17-25 .

Wolke, D., Tippett, N., \& Dantchev, S. (2015). Bullying in the family: Sibling bullying. The Lancet Psychiatry, 2(10), 917-929. 